Accuracy Assessment of Post-processing Kinematic Georeferencing Based on Real-time Kinematic Unmanned Aerial Vehicle and Structure-from-motion Photogrammetry: Topographic Measurements of a Riverbed in a Small Watershed with a Check Dam

This paper was downloaded from TechRxiv (https://www.techrxiv.org).

\section{LICENSE}

CC BY 4.0

SUBMISSION DATE / POSTED DATE

$11-11-2021 / 16-11-2021$

\section{CITATION}

Hayamizu, Masato; Nakata, Yasutaka (2021): Accuracy Assessment of Post-processing Kinematic Georeferencing Based on Real-time Kinematic Unmanned Aerial Vehicle and Structure-from-motion Photogrammetry: Topographic Measurements of a Riverbed in a Small Watershed with a Check Dam. TechRxiv. Preprint. https://doi.org/10.36227/techrxiv.16987960.v1

$\mathrm{DOI}$ 


\title{
Accuracy Assessment of Post-processing Kinematic Georeferencing Based on Real-time Kinematic Unmanned Aerial Vehicle and Structure-from-motion Photogrammetry: Topographic Measurements of a Riverbed in a Small Watershed with a Check Dam
}

\author{
Masato Hayamizu and Yasutaka Nakata
}

\begin{abstract}
To obtain an accurate digital surface model of the small watershed topography of a forested area while reducing time and labor costs, we used a consumer-grade unmanned aerial vehicle (UAV) with a build-in real-time kinematic global navigation satellite system. The applicability of structure-from-motion (SfM) multi-view stereo processing with post-processing kinematic (PPK) correction of the positional coordinate data (the UAV-PPKSfM method) was tested. Nine verification points were set up in a small $\left(0.5 \mathrm{~km}^{2}\right)$ watershed, based on a check dam in the headwaters of a forest area. The location information of the verification points extracted from the digital surface model acquired by UAV-PPK-SfM and the overall working time were compared with the corresponding location information and working time of a traditional field survey using a total station. The results showed that the vertical error between the total station and each verification point at an altitude of $150 \mathrm{~m}$ ranged from 0.006 to $0.181 \mathrm{~m}$. The working time of the UAV-PK-SfM survey was $10 \%$ of that of the total station survey $(30 \mathrm{~min})$. The UAV-PPK-SfM workflow proposed in this study shows that wide-area, nondestructive topographic surveying, including fluvial geomorphological mapping, is possible with a vertical error of $\pm 0.2 \mathrm{~m}$ in small watersheds $\left(<0.5 \mathbf{k m}^{2}\right)$. This method will be useful for rapid topographic surveying in inaccessible areas during disasters, such as monitoring debris flow at check dam sites, and for efficient topographic mapping of steep valleys in forested areas where the positioning of ground control points is a laborious task.
\end{abstract}

This work was supported by a research fund from the Hokkaido Research Organization (M. Hayamizu and Y. Nakata contributed equally to this work; Corresponding author: M. Hayamizu.).
Index Terms-Unmanned aerial vehicle, post-processing kinematic, structure-from-motion, real-time kinematic, ground control point, headwater stream

\section{INTRODUCTION}

$O$ mall headwater streams are a major source of initial geomorphic events, such as soil erosion and debris flow [1], [2]. The construction of check dams that control soil erosion and debris flow is the most adopted technique to reduce the risk of disasters originating from headwater channels [3], [4]. In case of small headwaters located in humid and temperate regions, check dams are constructed to control large debris flows and sediment erosion, with the aim of developing and conserving forest vegetation [5], [6]. Therefore, it is necessary to develop a continuous monitoring method for check dams constructed in various environments, including those in small headwater riverbeds, and to assess the impacts of dam construction.

Traditionally, total station surveying has been adopted for identifying topographic changes after the construction of check dams in small headwater streams [7]. Point-by-point surveying with total stations is time-consuming; however, advances in surface measurement techniques utilizing proximal remote sensing methods have assisted in overcoming these time constraints [8]. For example, terrestrial laser scanners (TLS) [9] and unmanned aerial vehicle (UAV) light detection and ranging (LiDAR) [10] can reconstruct the three-dimensional (3D) shape of an object using laser light and survey the topographical information of a limited area at high resolution. Moreover, UAVs and structure-from-motion (SfM) multi-view stereo (MVS) can reconstruct the 3D shape of an object from aerial

Both Authors are with the Forestry Research Institute, Hokkaido Research Organization, Higashiyama, Koshunai, Bibai, Hokkaido 079-0198, Japan (email: hayamizu-masato@hro.or.jp; Tel: +81-0126-63-4164). 
$>$ REPLACE THIS LINE WITH YOUR MANUSCRIPT ID NUMBER (DOUBLE-CLICK HERE TO EDIT) <

photographs, similar to reconstructions from TLS and UAVLiDAR [11], [12]. These area-wide methods are capable of high-resolution topographic surveys, with spatial resolutions ranging from a few centimeters to a few millimeters [13]. The cost of the survey, however, is relatively lower for UAV-SfMMVS than for TLS or UAV-Lidar [11], [12]. Therefore, UAVSfM-MVS is widely applied in monitoring applications where extensive high-resolution 3D terrain information is required at a low cost [3], [14], [15].

UAV-SfM-MVS requires accurate georeferencing using ground control points (GCPs). Several methodological studies have demonstrated that GCP-based georeferencing ensures the accuracy of UAV data and digital surface models (DSMs) [17][19]. However, GCP-based georeferencing is time-consuming and exhibits high labor cost, as well as disturbs the topography of the observation target. This is because the observation target surroundings must be surveyed in advance and appropriate positioning must be ensured before the UAV survey is undertaken. In addition, the accuracy of UAV-SfM photogrammetry depends on the number and layout of the GCPs; furthermore, monitoring surveys pose additional problems because of the mobility of GCPs (owing to weather effects and surface deformation) [20]. In particular, the inability to position GCPs uniformly is a major limiting factor in maintaining the accuracy of UAV-SfM surveys, especially in headwater areas where topographic changes occur frequently owing to debris flow [21].

Direct georeferencing based on non-destructive and highprecision global navigation satellite systems (GNSSs) that do not involve GCP installation is a key factor in overcoming this issue, but it requires the accurate geo-tagging of aerial images during the exposure period [22]. For several years, the development of high-quality inertial measurement units, GNSS technology, and dedicated real-time kinetic (RTK) and postprocessing kinematic (PPK) solutions for UAVs have enabled the accurate measurement of UAV camera position and orientation. The DJI Phantom 4 RTK (P4R)-UAV (DJI, China), which is directly integrated with an RTK-GNSS, records highly accurate position information [23]-[26]. It is possible to acquire a high-precision DSM without installing GCPs even in forested areas with many undulations and obstructions [23], [24]. Moreover, the RTK-UAV method has potential for application in areas with complex terrain, where measurement is difficult owing to high interference from tree canopies. However, this method is yet to be widely evaluated for forested areas or the valley terrains of small watersheds that exhibit large differences in elevation.

In this study, we aim to verify whether PPK processing of the location information appended to the aerial images recorded by RTK-UAV before SfM processing enables surveying with high accuracy in inaccessible areas. The objective of this study is to verify the efficiency of the UAV-PPK-SfM workflow in the context of the topographic measurement of riverbeds with check dams in forested areas within small watersheds.

\section{MetHODS}

\section{A. Study Site}

The study site is located in Naie Town, Sorachi, in the central part of Hokkaido Prefecture, Japan (Fig. 1a). Sorachi Subprefecture has an average annual temperature of $8.0^{\circ} \mathrm{C}$, annual precipitation of $1096 \mathrm{~mm}$, and falls within the cool temperate zone (Japan Meteorological Agency, 2020). The vegetation of this site comprises deciduous broad-leaved trees and evergreen conifers. The deciduous broad-leaved trees are particularly prominent in the study area. The study site comprises an area of $0.5 \mathrm{~km}^{2}$, with an altitudinal range of approximately $60 \mathrm{~m}$. The check dam designated as the base point for verification was built in 1983 in a sub-watershed of the study area. Topographical data for the period before 1983 were available in erosion control ledgers, and hence, the longitudinal slope of the riverbed before the construction of the check dam could be recreated from past records.

\section{B. Data collection}

Fig. 2 illustrates the overall process of data collection and analysis used in this study. Nine verification points were installed across the study area before the survey (Fig. 1b). On November 5, 2020, one verification point on the check dam was surveyed with a dual-frequency RTK-GNSS receiver (Trimble Inc., Sunnyvale, California, USA) for $30 \mathrm{~min}$, and this point was considered as the reference point. Further, the remaining eight verification points were surveyed with the help of a total station. On November 6, 2020, a $0.5 \mathrm{~km}^{2}$ area, containing the same verification points that were measured by the total station, was aerial photographed by RTK-UAV to obtain positional coordinates using the P4R. The survey period was conducted during the pre-winter season, during which deciduous broadleaved trees shed their leaves. The wind speeds at all points were less than $1 \mathrm{~m} / \mathrm{s}$. The aerial shooting conditions for P4R were as follows: shooting altitudes of $70 \mathrm{~m} / 150 \mathrm{~m}$, ground sampling distance of 1.92/4.11 cm/pix, shutter interval of $2 \mathrm{~s}$, overlap of $80 \%$, and side lap of $80 \%$. The angle of the UAV camera was set vertically downward. The DJI GS RTK application was used to set the flight path and autonomous flight of the P4R.

\section{Data processing}

1) PPK analysis: In this study, we performed PPK correction of the location information (geotags) assigned to the photographs taken by the RTK-UAV (Fig. 2). Rinex and Timestamp files were generated in the folder after an autonomous flight using P4R. The generated Rinex and Timestamp files were fed into the software in the required format; subsequently, PPK processing was performed. The electronic reference point correction information (Rinex file) required for post-processing correction was downloaded from the Geospatial Information Authority of Japan website. The PPK software used was KLAU PPK-J Desktop for DJI RTK version 1.04 (KLAU Geomatics Inc.).

2) Generation of point cloud and digital surface models: All UAV images used in the analysis exhibited the RTK Fix solution. DSMs were generated using Agisoft Metashape Professional Edition software (Agisoft LLC, St. Petersburg, Russia), version 1.6.5. This software can restore a 3D shape 
$>$ REPLACE THIS LINE WITH YOUR MANUSCRIPT ID NUMBER (DOUBLE-CLICK HERE TO EDIT) <

from multiple photographs using the principles of photogrammetry. Subsequently, the descriptors of the points were used for object reconstruction across successive images. The linear exterior orientation parameters were read from the exchangeable image file format ("EXIF"). The 3D model was created by repeating the process of extracting commonalities from a pair of images.

\section{Assessment of accuracy}

We generated DSMs using RTK-UAV, PPK, and SfM-MVS photogrammetry (Fig. 2). To investigate the accuracy and energy-efficiency of the UAV-PPK-SfM workflow, a small check dam located in the headwaters of a forested area was used as a base point, and nine verification points were established upstream and downstream of the dam. To compare the positioning information and working time of the UAV-PPKSfM survey and the conventional survey (total station method), the coordinates, which were extracted from the DSMs and generated by the UAV-PPK-SfM were compared with the total station survey results. The overall working times for both methods were measured. Aerial photogrammetry was conducted in an area of $0.5 \mathrm{~km}^{2}$ with an elevation range of 40 $\mathrm{m}$ in the headwaters of a forested area under different flight conditions $(70 \mathrm{~m}$ and $150 \mathrm{~m})$; it was conducted using a consumer-grade UAV equipped with a built-in RTK-GNSS. The aerial images were processed using PPK-SfM, and the coordinates of the verification points were extracted from the created DSMs.

\section{RESULTS AND DISCUSSION}

\section{A. UAV-PPK-SfM method in direct georeferencing}

The UAV-PPK-SfM method could acquire DSMs with a horizontal root mean square error (RMSE) of $0.215-0.429 \mathrm{~m}$ and a vertical RMSE of $0.103-0.394 \mathrm{~m}$ without GCPs in the forested area of a small watershed (Table I). In particular, the vertical error, based on the total station results for each verification point, ranged from $0.006-0.181 \mathrm{~m}$ at an altitude of $150 \mathrm{~m}$ (Table II). These results indicate that the proposed method can be used to indirectly georeference the topography of a forested area within a small watershed (area: $0.5 \mathrm{~km}^{2}$; elevation range: $40 \mathrm{~m}$ ); additionally, this can be conducted in a single step without using GCPs.

At a flight altitude of $150 \mathrm{~m}$, the horizontal and vertical errors were significantly more acceptable (within acceptable limits) than those at a flight altitude of $70 \mathrm{~m}$ (Table I and II). Results from the UAV-SfM method suggest a high overlap rate (> $80 \%$ ) is required to obtain an accurate DSM [27], [28]. In this study, the overlap ratio was set to $80 \%$ for both the $70 \mathrm{~m}$ and $150 \mathrm{~m}$ flight altitudes. However, an appropriate overlap ratio cannot be ensured at low flight altitudes because of the varying distance from the UAV camera to the ground, owing to the slope and undulation of the terrain. Moreover, some of the 107 photographs captured at the low altitude $(70 \mathrm{~m})$ were not selected for SfM processing owing to low overlap rates. This suggests that photogrammetry conducted at a higher altitude $(150 \mathrm{~m})$ is more accurate than that conducted at a lower altitude $(70 \mathrm{~m})$ in rugged small watersheds, as the SfM-MVS process assures an appropriate overlap rate.

\section{B. UAV-PPK-SfM workflow}

The UAV-PPK-SfM method could survey the area in approximately $10 \%$ of the working time of the total station method (Fig. 3). The field survey duration was only approximately $1 \%(3 \mathrm{~min})$ of the total station time, despite acquiring more extensive aerial topographic information, as the UAV-PPK-SfM method can avoid most of the steps required in conventional field surveys.

Several studies have indicated the labor-saving effects of RTK-UAVs, as they do not require GCP installation or the transportation of equipment (ground markers, GNSS receivers, antennas, and installation equipment) that is required in conventional UAV surveying [22], [25]. In addition, topographic surveying with RTK-UAV is expected to reduce the risk of accidents and injuries during fieldwork and the person-hours required [23], [24]. The UAV-PPK-SfM method demonstrated in this study is a safe alternative for conducting topographic measurements solely using aircraft flight information. It is less time-consuming, especially in areas where RTK correction is difficult owing to interference from trees and other terrain features.

\section{Applicability of UAV-PPK-SfM methods for topographic measurement}

The UAV-PPK-SfM method confirmed that, owing to sedimentation during the 37 years since the dam was built, the riverbed on the upstream side of the check dam was almost equal to the height of the embankment. This height was also similar to the height of the total station in the conventional survey method (Fig. 4 and 5). In addition, the survey results showed that the slope of the riverbed is presently gentler than when the dam was built in 1983 (Fig. 4 and 5). These results demonstrate that the UAV-PPK-SfM method can be applied to the terrain around check dams under existing conditions to verify the efficiency of the check dam since its construction. Furthermore, the UAV-PPK-SfM method could acquire topographic information for the area around the check dam with an accuracy of $<0.3 \mathrm{~m}$ in approximately $30 \mathrm{~min}$ (Table I and Fig. 4 and 5). The considerable labor-saving effect of the UAVPPK-SfM method suggests that it can be widely applied not only to monitor check dam sites but also to analyze the topography of small watersheds and to monitor topographic changes in forested areas.

Small watersheds in mountain catchments, where vegetation is scarce and debris flows are more frequent, have previously been surveyed using the UAV-SfM method [3]. Most studies were compelled to distribute multiple GCPs uniformly for accurate topographic surveying rather than positioning more GCPs in hazardous areas with high-frequency debris flow, for example in [15] and [21]. In addition, UAV-SfM photogrammetry could not avoid uncertainties owing to technical limitations and differences in the accuracy of the GCP measurements, despite cautious placement of the GCPs, which is an important factor for reproducibility [14]. In contrast, the UAV-PPK-SfM method, the accuracy and efficiency of which has been demonstrated in this study, allows frequent and rapid remote sensing topographic surveys of small headwater riverbeds, as it does not require GCP installation or involve tree interference. 


\section{CONCLUSIONS}

This study demonstrates that the UAV-PPK-SfM method is capable of topographic surveys, providing accuracies $<0.3 \mathrm{~m}$, even in a small watershed with a check dam in a forested area. The accuracies achieved in the DSMs, after 30 min or less of UAV-PPK-SfM surveying at $150 \mathrm{~m}$, were indicated by RMSEs of $0.215 \mathrm{~m}$ and $0.103 \mathrm{~m}$ in the horizontal and vertical directions, respectively. Direct georeferencing using a UAV-PPK-SfM workflow enables rapid, safe, and accurate surveying and provides the non-destructive and extensive information needed for terrain monitoring around check dams within $3 \mathrm{~min}$ of fieldwork. However, this study was conducted during a limited period when the trees were shedding their leaves. Thus, the applicability of this method to other periods of the year needs further investigation. The proposed method can be applied for monitoring topographic changes caused by disasters, such as soil erosion and debris flow.

\section{ACKNOWLEDGMENT}

We thank Dr. T. Ogura and E. Masuto for his assistance and sharing valuable information. We thank Editage for English language editing.

\section{AVAILABILITY OF DATA AND MATERIALS}

The data used in this study are available from the authors on request.

\section{COMPETING INTERESTS}

The authors declare no conflicts of interest.

\section{REFERENCES}

[1] L. Benda, M. A. Hassan, M. Church, and C. L. May, "Geomorphology of Steepland headwaters: the transition from hillslopes to Channels," JAWRA, vol. 41, pp. 835-851, Aug. 2005, doi: 10.1111/j.17521688.2005.tb03773.x.

[2] F. Imaizumi, T. Masui, Y. Yokota, H. Tsunetaka, Y. S. Hayakawa, and N. Hotta, "Initiation and runout characteristics of debris flow surges in Ohya landslide scar, Japan," Geomorphology, vol. 339, pp. 58-69, Apr. 2019, doi: 10.1016/j.geomorph.2019.04.026.

[3] N. A. Abbasi, X. Xu, M. E. Lucas-Borja, W. Dang, and B. Liu, "The use of check dams in watershed management projects: examples from around the world," Sci. Total Environ., vol. 676, pp. 683-691, Aug. 2019, doi: $\underline{10.1016 / j . s c i t o t e n v .2019 .04 .249}$.

[4] G. Piton, et al., "Why do we build check dams in Alpine streams? An historical perspective from the French experience: A review of the subtle knowledge of $19^{\text {th }}$ century torrent-control-engineers," Earth Surf. Proc. Land., vol. 42, pp. 91-108, Jan. 2017, doi: 10.1002/esp.3967.

[5] H. Chanson, "Sabo check dams - Mountain protection systems in Japan," Int. J. River Basin Manag., vol. 2, pp. 301-307, Dec. 2004, doi: $10.1080 / 15715124.2004 .9635240$.

[6] Y. Okada, "Functions of Chisan dams in large-scale granular mass-flow experiments on Sakurajima volcano pumiceous clasts," J. For. Res., vol. 19, pp. 493-500, Feb. 2014, doi: 10.1007/s10310-014-0443-4.

[7] M. A. Lenzi, and F. Comiti, "Local scouring and morphological adjustments in steep channels with check-dam sequences," Geomorphology, vol. 55, pp. 97-109, Sep. 2003, doi: 10.1016/S0169555X(03)00134-X.

[8] T. Mill, A. Alt, and R. Liias, "Combined 3D building surveying techniques - terrestrial laser scanning (TLS) and total station surveying for BIM Data Management purposes," J. Civ. Eng. Manag., vol. 19, pp. S23-S32, Apr. 2013, doi: 10.3846/13923730.2013.795187.

[9] T. Mill, A. Ellmann, A. Aavik, M. Horemuz, and S. Sillamäe, "Determining ranges and spatial distribution of road frost heave by terrestrial laser scanning," Baltic J. Road Bridge Eng., vol. 9, pp. 225234, Sep. 2014, doi: 10.3846/bjirbe.2014.28.

[10] U. Vepakomma, and D. Cormier, "Potential of multi-temporal UAVBORNE lidar in assessing effectiveness of silvicultural treatments," Int. Arch. Photogramm. Remote Sens. Spatial Inf. Sci., vol. XLII-2/W6, pp. 393-397, Sep. 2017, doi: 10.5194/isprs-archives-XLII-2-W6-393-2017.

[11] M. A. Fonstad, J. T. Dietrich, B. C. Courville, J. L. Jensen, and P. E. Carbonneau, "Topographic structure from motion: a new development in photogrammetric measurement: topographic structure from motion," Earth Surf. Proc. Land., vol. 38, pp. 421-430, Mar. 2013, doi: 10.1002/esp.3366.

[12] P. Tarolli, "High-resolution topography for understanding Earth surface processes: opportunities and challenges," Geomorphology, vol. 216, pp. 295-312, Jul. 2014, doi: 10.1016/..geomorph.2014.03.008.

[13] B. Brede, A. Lau, H. M. Bartholomeus, and L. Kooistra, "Comparing RIEGL RiCOPTER UAV LiDAR derived canopy height and DBH with terrestrial LiDAR,” Sensors, vol. 17, p. 2371, Oct. 2017, doi: 10.3390/s17102371.

[14] F. Clapuyt, V. Vanacker, and K. Van Oost, "Reproducibility of UAVbased earth topography reconstructions based on Structure-from-Motion algorithms," Geomorphology, vol. 260, pp. 4-15, May 2016 doi: 10.1016/i.geomorph.2015.05.011.

[15] S. Cucchiaro, et al., "Geomorphic effectiveness of check dams in a debris-flow catchment using multi-temporal topographic surveys," Catena, vol. 174, pp. 73-83, Mar. 2019 doi: 10.1016/j.catena.2018.11.004.

[16] S. Cucchiaro, et al., "Multiplatform-SfM and TLS data fusion for monitoring agricultural terraces in complex topographic and landcover conditions," Remote Sens., vol. 12, p. 1946, Jun. 2020, doi: 10.3390/rs12121946.

[17] M. R James, S. Robson, and M. W. Smith, "3-D uncertainty-based topographic change detection with structure-from-motion photogrammetry: precision maps for ground control and directly georeferenced surveys: 3-D uncertainty-based change detection for SfM surveys," Earth Surf. Proc. Land., vol. 42, pp. 1769-1788, Feb. 2017 doi: $10.1002 /$ esp. 4125 .

[18] M. R. James, and S. Robson, "Straightforward reconstruction of 3D surfaces and topography with a camera: accuracy and geoscience application," J. Geophys. Res., vol. 117, Aug. 2012, doi: 10.1029/2011JF002289.

[19] D. Turner, A. Lucieer, and S. M. De Jong, "Time series analysis of landslide dynamics using an unmanned aerial vehicle (UAV)," Remote Sens., vol. 7, pp. 1736-1757, Jan. 2015, doi: 10.3390/rs70201736.

[20] T. N. Tonkin, and N. G. Midgley, "Ground-control networks for image based surface reconstruction: an investigation of optimum survey designs using UAV derived imagery and structure-from-motion photogrammetry," Remote Sens., vol. 8, p. 786, Sep. 2016, doi: 10.3390/rs8090786.

[21] H. Tsunetaka, N. Hotta, Y. S. Hayakawa, and F. Imaizumi, "Spatial accuracy assessment of unmanned aerial vehicle-based structures from motion multi-view stereo photogrammetry for geomorphic observations in initiation zones of debris flows, Ohya landslide, Japan," Prog. Earth Planet. Sci., vol. 7, p. 24, Jun. 2020, doi: 10.1186/s40645-020-00336-0.

[22] K. Iizuka, T. Ogura, Y. Akiyama, H. Yamauchi, T. Hashimoto, and Y. Yamada, "Improving the 3D model accuracy with a post-processing kinematic (PPK) method for UAS surveys," Geocarto. Int., pp. 1-21, Jan. 2021, doi: $10.1080 / 10106049.2021 .1882004$.

[23] Y. Nakata, M. Hayamizu, K. Koshimizu, F. Takeuchi, M. Ebina, and H. Sato, "Accuracy assessment of topographic measurements and monitoring of topographic changes using RTK-UAV in landslide area caused by 2018 Hokkaido Eastern Iburi Earthquake," Landsc. Ecol. Manag., vol. 25, pp. 43-52, Jun. 2020, doi: $10.5738 /$ jale. 25.43

[24] Y. Nakata, M. Hayamizu, N. Ishiyama, and H. Torita, "Observation of diurnal ground surface changes due to freeze-thaw action by real-time kinematic unmanned aerial vehicle," Remote Sens., vol. 13, p. 2167, May 2021, doi: $10.3390 /$ rs 13112167 .

[25] H. Obanawa, S. Sakanoue, and T. Yagi, "Evaluating the applicability of RTK-UAV for field management," IGARSS 2019-2019 IEEE Int. Geosci. Remote Sens. Symp., pp. 9090-9092, Jul. 2019, doi: 10.1109/IGARSS.2019.8897895.

[26] M. V. Peppa, J. Hall, J. Goodyear, and J. P. Mills, "Photogrammetric assessment and comparison of DJI phantom 4 pro and phantom 4 RTK small unmanned aircraft systems," Int. Arch. Photogramm. Remote Sens. 
$>$ REPLACE THIS LINE WITH YOUR MANUSCRIPT ID NUMBER (DOUBLE-CLICK HERE TO EDIT) <

Spatial Inf. Sci, vol. XLII/W13, pp. 503-509, Jun. 2019, doi: 10.5194/isprs-archives-XLII-2-W13-503-2019.

[27] J. P. Dandois, M. Olano, and E. C. Ellis, "Optimal altitude, overlap, and weather conditions for computer vision UAV estimates of forest structure," Remote Sens., vol. 7, pp. 13895-13920, Oct. 2015, doi: $10.3390 / \mathrm{rs} 71013895$.

[28] M. Róg and A. Rzonca, "The impact of photo overlap, the number of control points and the method of camera calibration on the accuracy of 3D model reconstruction," GaEE, vol. 15, pp. 67-87, Mar. 2021, doi: $\underline{10.7494 / \text { geom.2021.15.2.67. }}$ 
FiguRES AND TABLES
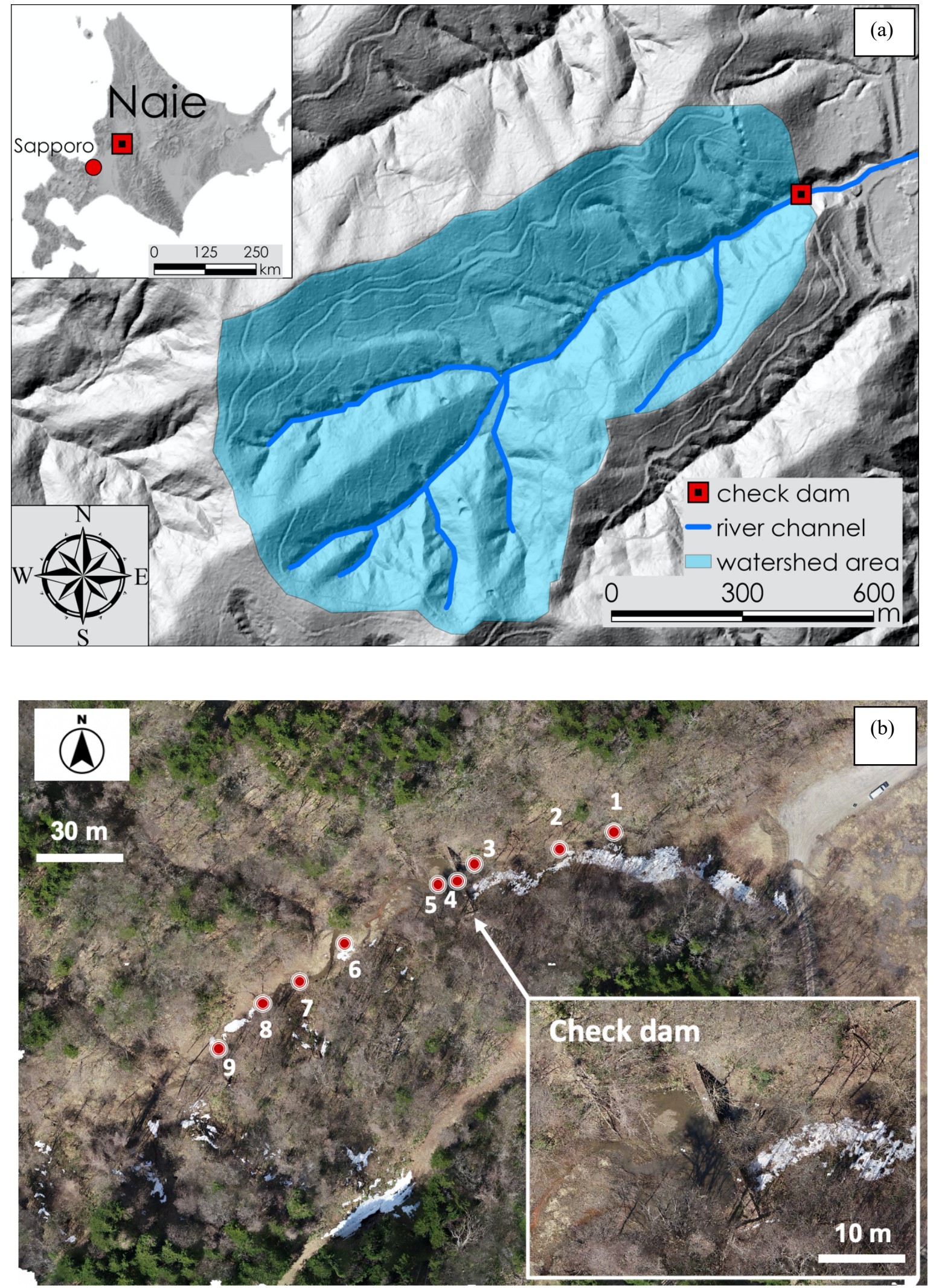

Fig. 1. (a) Maps of the study area produced from Google maps. (b) UAV imagery. Red circles indicate verification points. 

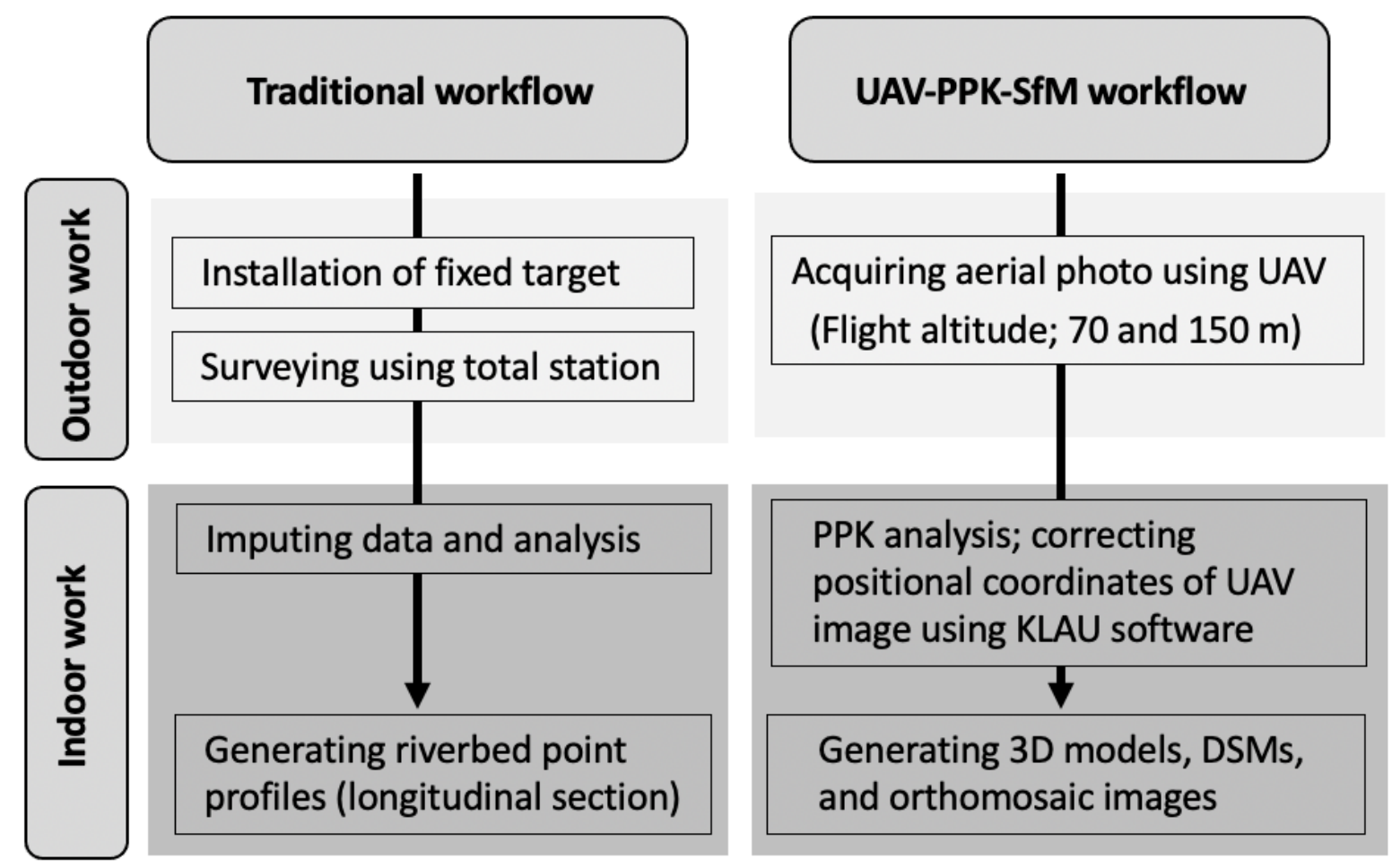

Fig. 2. Flowchart of the overall process of data collection and analysis in this study.
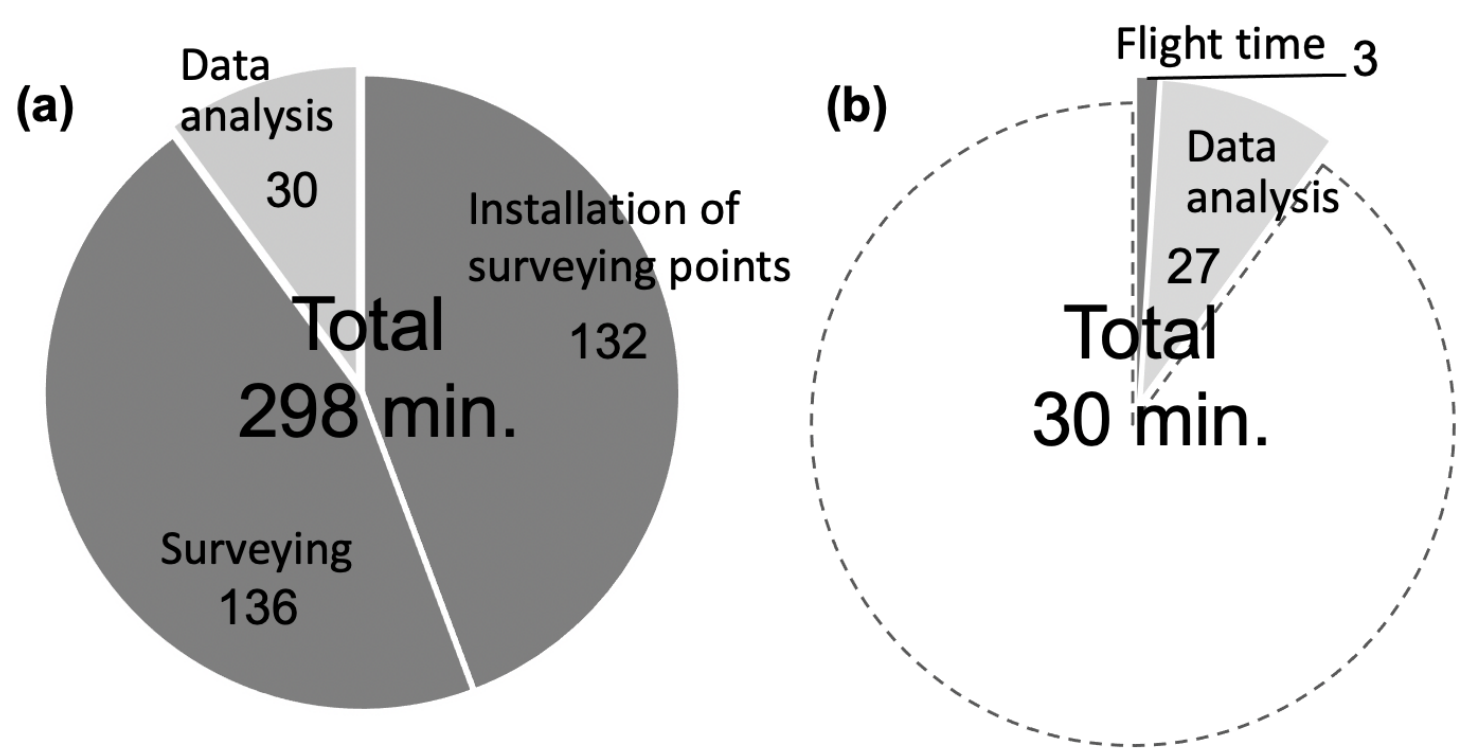

\section{Outdoor works}

\section{Indoor works}

Fig. 3. Work time of (a) traditional method (total station survey) and (b) UAV-RTK-SfM method at a flight altitude of $150 \mathrm{~m}$. 


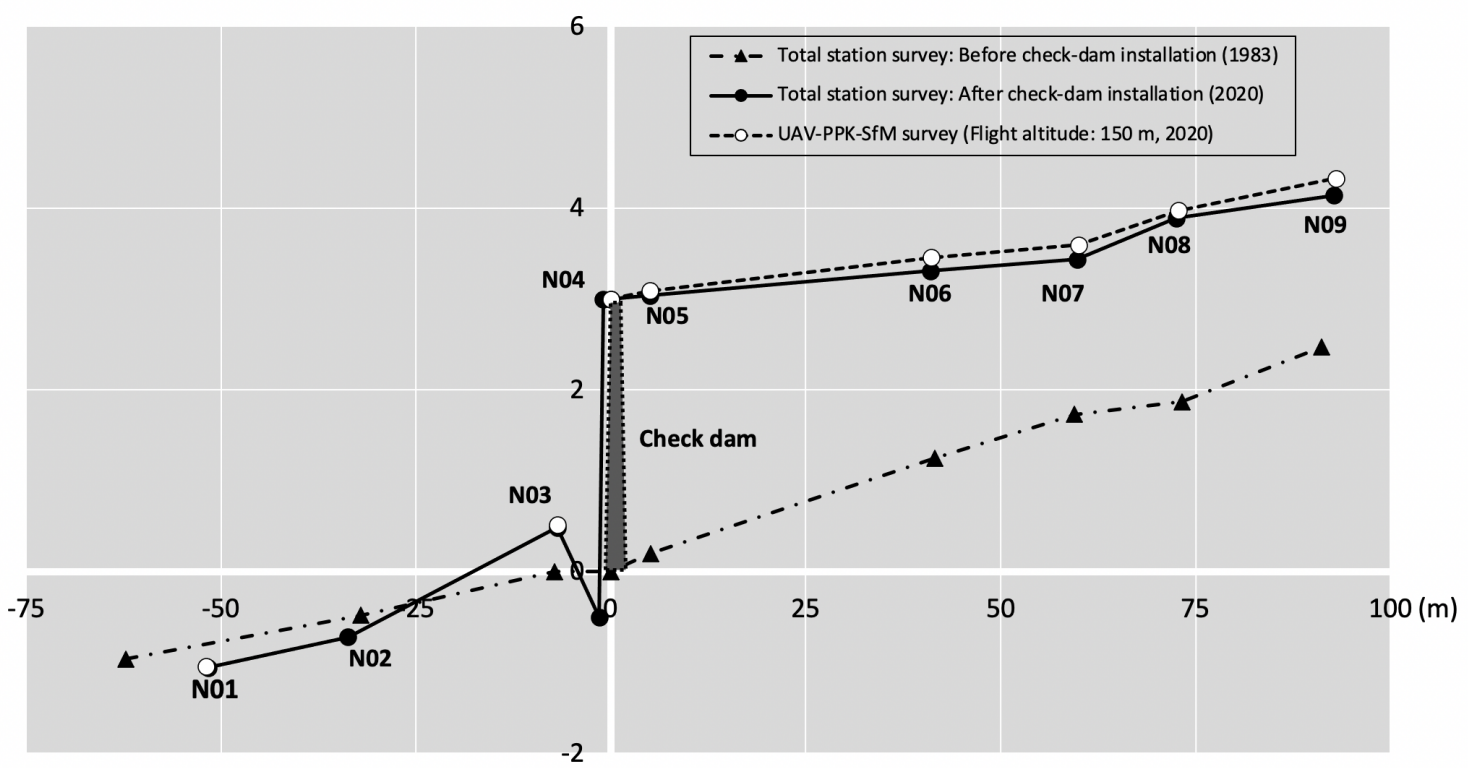

(m)

Fig. 4. Riverbed topography before (1983) and after (2020) the installation of the check dam, using total station and UAV-PPK-SfM methods.

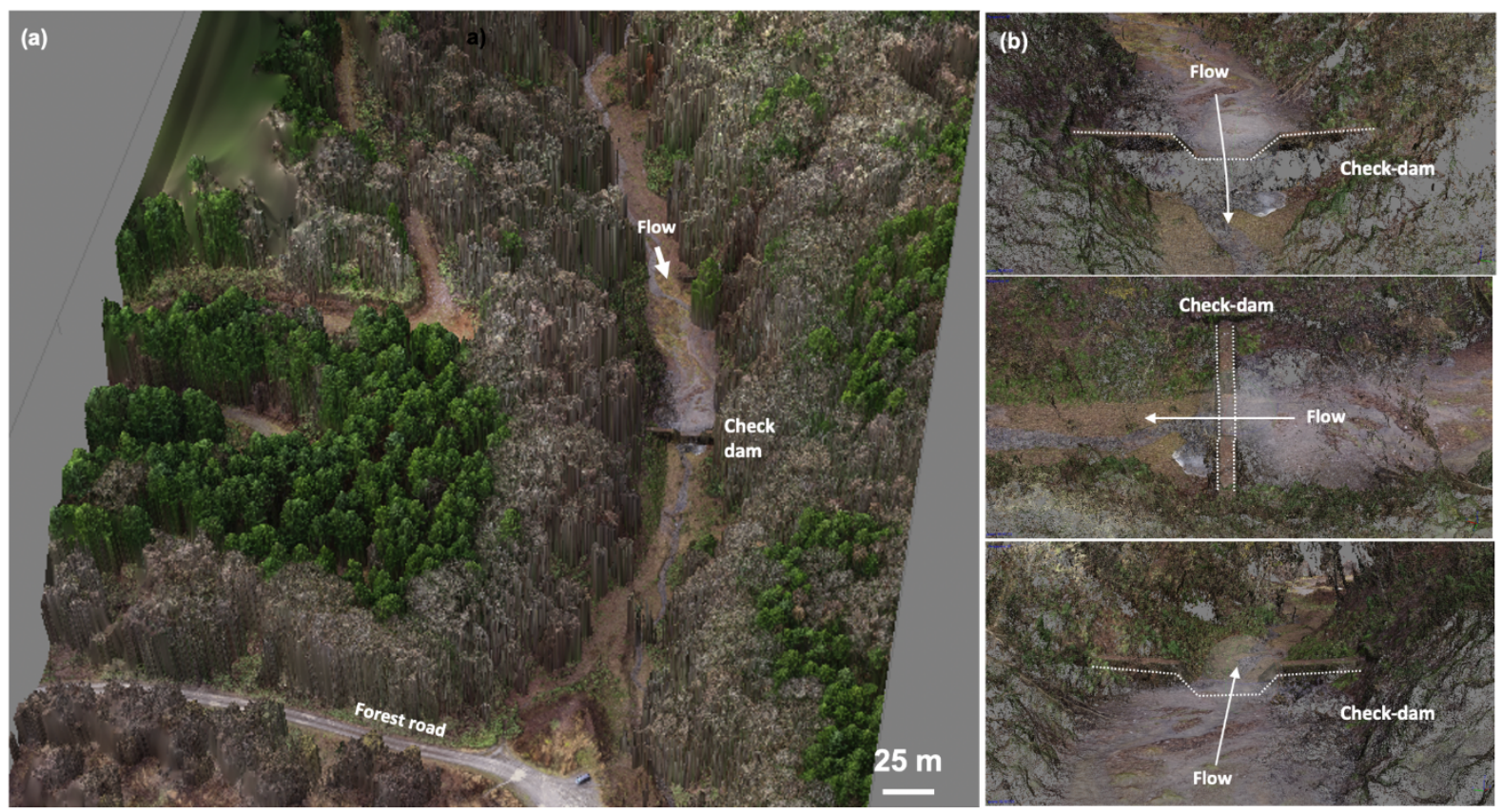

Fig. 5. Results of the UAV-PPK-SfM measurements. (a) 3D model and (b) point cloud images shown from three perspectives: downstream, plan, and upstream views. 


\section{TABLE I}

SUMMARY OF THE UAV-PPK-SFM METHOD RESULTS FOR EACH FLIGHT CONDITION. MISSING POINTS IS THE NUMBER OF GROUND CONTROL POINTS (GCPS) OUT OF THE NINE GCPS INSTALLED THAT WERE NOT EXTRACTABLE FROM THE DSM MODEL. RMSE (HORIZONTAL AND VERTICAL) SHOWS THE ROOT MEAN SQUARE ERROR BETWEEN THE DSM PRODUCED FROM THE AERIAL IMAGES AND EACH VERIFICATION POINT SURVEYED IN THE FIELD UNDER THE RESPECTIVE CONDITIONS

\begin{tabular}{ccccccc}
\hline $\begin{array}{l}\text { Flight altitude } \\
(\mathrm{m})\end{array}$ & $\begin{array}{c}\text { Overlap } \\
\text { rate }(\%)\end{array}$ & $\begin{array}{c}\text { Working } \\
\text { time (min) }\end{array}$ & $\begin{array}{c}\text { No. of } \\
\text { photos }\end{array}$ & $\begin{array}{c}\text { Missing points } \\
\text { / 9 GCPs }\end{array}$ & \multicolumn{2}{c}{ RMSE (m) } \\
& & & & & \\
70 & 80 & 32 & 107 & 2 & 0.429 & 0.394 \\
150 & 80 & 30 & 42 & 1 & 0.215 & 0.103 \\
\hline
\end{tabular}




\section{TABLE II}

SUMMARY OF THE ERRORS FOR EACH VERIFICATION POINT CALCULATED BY COMPARING THE DSM PRODUCED FROM AERIAL IMAGES AND FIELD SURVEYS USING TOTAL STATIONS AND GLOBAL NAVIGATION SATELLITE SYSTEM.

\begin{tabular}{|c|c|c|c|c|c|c|c|}
\hline \multirow{2}{*}{$\begin{array}{l}\text { Flight } \\
\text { altitude } \\
\text { id }\end{array}$} & \multicolumn{3}{|l|}{$70 \mathrm{~m}$} & \multicolumn{3}{|l|}{$150 \mathrm{~m}$} & \multirow[b]{2}{*}{ site characteristics } \\
\hline & $\mathrm{x}$ error & $\mathrm{y}$ error & $z$ error & $\mathrm{x}$ error & y error & $\mathrm{z}$ error & \\
\hline N01 & - & - & - & 0.448 & -0.351 & 0.012 & riverbed \\
\hline N02 & - & - & - & - & - & - & riverbed \\
\hline N03 & 0.312 & -0.182 & 0.339 & 0.181 & -0.166 & 0.022 & riverbed \\
\hline N04 & 0.216 & -0.128 & 0.357 & 0.075 & -0.080 & -0.006 & check dam \\
\hline N05 & 0.253 & -0.150 & 0.354 & 0.129 & -0.169 & 0.046 & riverbed \\
\hline N06 & 0.092 & -0.080 & 0.298 & -0.087 & -0.062 & 0.141 & riverbed \\
\hline N07 & -0.006 & -0.031 & 0.333 & -0.184 & -0.027 & 0.152 & riverbed \\
\hline N08 & -0.107 & -0.011 & 0.342 & -0.308 & -0.002 & -0.081 & riverbed \\
\hline N09 & -0.387 & 1.323 & 0.636 & -0.393 & 0.027 & 0.181 & riverbed \\
\hline RMSE & 0.232 & 0.511 & 0.394 & 0.261 & 0.154 & 0.103 & \\
\hline
\end{tabular}

-; coordinate information could not be extracted owing to interference by trees 